\title{
Differentiated product markets : an experimental test of two equilibrium concepts
}

Citation for published version (APA):

Peeters, R. J. A. P., \& Strobel, M. (2005). Differentiated product markets : an experimental test of two equilibrium concepts. METEOR, Maastricht University School of Business and Economics. METEOR Research Memorandum No. 020 https://doi.org/10.26481/umamet.2005020

Document status and date:

Published: 01/01/2005

DOI:

10.26481/umamet.2005020

Document Version:

Publisher's PDF, also known as Version of record

\section{Please check the document version of this publication:}

- A submitted manuscript is the version of the article upon submission and before peer-review. There can be important differences between the submitted version and the official published version of record.

People interested in the research are advised to contact the author for the final version of the publication, or visit the DOI to the publisher's website.

- The final author version and the galley proof are versions of the publication after peer review.

- The final published version features the final layout of the paper including the volume, issue and page numbers.

Link to publication

\footnotetext{
General rights rights.

- You may freely distribute the URL identifying the publication in the public portal. please follow below link for the End User Agreement:

www.umlib.nl/taverne-license

Take down policy

If you believe that this document breaches copyright please contact us at:

repository@maastrichtuniversity.nl

providing details and we will investigate your claim.
}

Copyright and moral rights for the publications made accessible in the public portal are retained by the authors and/or other copyright owners and it is a condition of accessing publications that users recognise and abide by the legal requirements associated with these

- Users may download and print one copy of any publication from the public portal for the purpose of private study or research.

- You may not further distribute the material or use it for any profit-making activity or commercial gain

If the publication is distributed under the terms of Article $25 \mathrm{fa}$ of the Dutch Copyright Act, indicated by the "Taverne" license above, 


\title{
Differentiated Product Markets An Experimental Test of Two Equilibrium Concepts*
}

\author{
Ronald Peeters ${ }^{\dagger} \quad$ Martin Strobel ${ }^{\dagger}$
}

July 2005

\begin{abstract}
In markets with differentiated products Bertrand-Nash equilibria in pure strategies may not exist. Mixed strategies are difficult to calculate. For these cases Morgan and Shy (2000) suggest an alternative solution concept, the undercut-proof equilibrium (UPE). While the Nash-equilibrium is motivated by the question of how ones own behavior influences one's payoff, the UPE is motivated by the question of how others' behavior influence one's payoff. We report on an experiment where we test these two concepts with respect to their comparative statics. Moreover we investigate the nature of subjects' underlying thinking process. Our results provide strong evidence against the UPE and in favor of Bertrand-Nash.
\end{abstract}

JEL Classification Codes: D43, D01, C91

Keywords: Differentiated Markets, Bertrand-Nash Equilibrium, Undercut-Proof Equilibrium, Experiment

\section{Introduction}

The Bertrand model with horizontally differentiated products is one of the simplest models of industrial organization. Firms produce products that differ from each other for example in form, color or location of provision. Consumers' preferences are heterogeneous and favor either one or the other product. Already Hotelling (1929, p.44) argued that differentiation serves as a barrier which protects a firm's "limited monopoly". Consider the market for books telling a particular novel as an example. Publisher A sells an English version of the novel while publisher B sells a Dutch version. In the standard Bertrand setting where language is not an issue (i.e. all consumers speak both languages), consumers simply go for the cheaper book. The consequences for the publishers' pricing decisions are quite harsh. If one firm is

${ }^{*}$ We thank Sabine Kröger, Wieland Müller, Jan Potters, Bettina Rockenbach, Martin Sefton, Markus Walzl and seminar and conference participants in Erfurt, Marseille (Games 2004) and Maastricht (SING 2005) for helpful comments as well as Saskia Schawo for excellent assistance during the experiments. Financing by METEOR (Maastricht research school of Economics of TEchnology and ORganizations) and NWO is gratefully acknowledged.

${ }^{\dagger}$ Department of Economics, Universiteit Maastricht, P.O. Box 616, 6200 MD, Maastricht, The Netherlands. E-mail: $\{$ R.Peeters,M.Strobel $\} @$ algec.unimaas.nl. 
slightly more expensive it will face zero demand and consequently will not earn any profits. If however the consumers consist of native English and native Dutch speakers who like to read books in their mother tongue, then the consequences of being more expensive are softened because some Dutch speakers will buy the Dutch version despite a higher price. How well the protection of the language barrier functions, depends on the consumer characteristics. In the example above the publisher of the English version is probably much better protected because the number of native English speakers being able to speak Dutch or willing to learn Dutch is supposedly very small while this is not true vice versa.

Despite the simplicity of the Bertrand model with differentiated products the solution might get quite complicated. For certain consumer characteristics it can be shown that an equilibrium in pure prices does not exist (see section 2.1 for a detailed explanation). While the existence of a mixed strategy equilibrium is guaranteed, such an equilibrium is difficult to interpret and only of limited use for application to real-life markets. Consequently some major contributions to this topic dealt with sufficient conditions of the existence of an equilibrium in pure strategies. Bester (1992) showed that a Bertrand-Nash equilibrium in pure pricing strategies exists when consumer tastes are sufficiently dispersed. Uniqueness is guaranteed under further restrictions on the dispersion of preferences.

But what happens if consumer characteristics are such that an equilibrium in pure prices does not exist? This is an important question because consumer characteristics are in reality exogenously given. They cannot be chosen conveniently.

Shilony (1977) analyzed a simple model were two firms produce two differentiated products. Each product is preferred by one consumer who has some additional cost (or disutility) if he buys the product of the other firm rather than his favorite. Shilony showed that there exists a unique symmetric equilibrium and derived a closed-form solution for it. The solution, however applies only to the case of a completely symmetric market with zero production cost.

In order to find a more intuitive solution, Morgan and Shy (2000) proposed the UndercutProof Equilibrium (UPE). The basic rationale of the UPE is different from the one of a Nash equilibrium. In verifying an equilibrium, players do not keep their opponents' strategies fixed and reason whether there is an incentive to deviate from a given strategy. Rather players keep their own strategy fixed and reason whether the opponents have an incentive to undercut (asking a price low enough to attract the complete demand). Although the rationale is not exactly the same as Stackelberg's model it shares some of its features, mainly the idea of a sequential price setting process. Players consider themselves as first movers with the others being able to react on their price. The big advantage of the UPE is that a unique solution in pure strategies always exists. Moreover it is easy to calculate (see Shy 2001).

The downside of the UPE is that it comes with two non-intuitive results with respect to the comparative statics. First, the equilibrium price of a firm depends more heavily on the production cost of the other firm than on the own production cost. This means that given 
a sufficiently dispersed bimodal and symmetric distribution in consumer characteristics, the firm with the higher production cost charges the lower price. This is in contrast to the relationship of the expected prices in the mixed Nash-equilibrium. A second consequence of the UPE (less unexpected) is that the firm which is favored by a larger number of consumers charges a lower price because it is more vulnerable to undercutting. This is again in contrast to the expected prices of the Nash equilibrium. Shy (2001, p.311) argues that the UPE result is closer to reality than the contradicting result of Bertrand-Nash. There remains, however, the question of causality. Is the price low because there are a lot of consumers or are there a lot of consumers because the price is low?

Summing up, Morgan and Shy (2000) provide a nice, reasonable equilibrium concept which has the advantages of existence and uniqueness but comes with some questionable properties in the comparative statics. In contrast the mixed Nash equilibrium is quite difficult to derive, but its comparative statics seems to be more intuitive. This situation calls for an experimental test of these different solution concepts. ${ }^{1}$

Besides the pure test of the adequacy of the different concepts there is also an interesting behavioral point of view: The experimental results should shed some light in general on the question, which behavioral paradigm, that of Nash or the UPE is closer to people's ways to make a decision. The Nash paradigm could be described as thinking how your strategy changes might affect your payoff while the UPE paradigm is about how others' behavior would influence your payoff.

In this paper we set out to investigate these questions. We conducted a experiment with 208 subjects in 15 sessions. We find that our data is much more in favor of Nash than in favor of UPE. Firms with higher production costs and firms with a larger consumer base do set a higher prices. Moreover we find some evidence that people think more along the Nash paradigm than along the UPE paradigm.

In the remainder of the paper we will specify the model in Section 2 and discuss the different solution concepts. In the following Sections 3 and 4 we report on the experimental design and the results, respectively. Section 5 concludes with a summary of results and some suggestions of the appropriateness of the different equilibrium concepts.

\section{The Basic Model}

All important points we are going to make in this paper are covered by the duopoly case. Hence we restrict the model and the analysis to it. In our story we have chosen location as the mode of differentiation. The model, however, applies to any kind of differentiation. Transportation costs represent disutility (switching-costs) for consuming a less preferred product.

\footnotetext{
${ }^{1}$ Bertrand competition in differentiated product markets has been experimentally studied to some extent in the past, see for example Huck, Normann and Oechssler (2000) and Kübler and Müller (2002) and references therein. All of these studies used a setup with a Bertrand-Nash equilibrium in pure strategies.
} 
Assume two different firms $A$ and $B$ who are located in two different cities correspondingly labeled $A$ and $B$. The two firms offer the same product. They have a constant unit production cost of $c_{A}$ and $c_{B}$, respectively. There are $n_{A}$ consumers located in city $A$ and $n_{B}$ consumers in city $B$. All consumers demand one unit of the product and attach a value of $\beta$ to it. We assume $\beta$ to be sufficiently high to ensure that all consumers will buy in equilibrium. Consumers may buy the product in their own city and pay the local firm's price or they travel to the other city and pay the price of the other firm and an additional fixed transportation cost equal of $\delta$. All market parameters are assumed to be common knowledge.

The game played consists of two stages where in the first stage the firms simultaneously and independently set their prices and in the second stage the consumers decide from which firm to buy or not to buy at all after having observed both prices. This model is solved by backwards induction.

\section{Stage 2 (consumers' decision)}

The utility functions of the city $A$ consumers and city $B$ consumers can formally be described as

$$
U_{i}= \begin{cases}\beta-p_{i} & \text { if consumer } i \text { buys from firm } i \\ \beta-p_{j}-\delta & \text { if consumer } i \text { buys from firm } j \\ 0 & \text { otherwise }\end{cases}
$$

where $i, j \in\{A, B\}$ and $i \neq j$.

Consumers maximize their utility which is the benefit they get from the good minus the cost to acquire it. Ties which may happen for the case of indifferent consumers are broken as to maximize welfare. This means that indifferent consumers buy rather than abstain and buy their own firm's product rather than the other firm's product. Once the two prices are announced, the amount of customers for each firm is computed by

$$
q_{i}= \begin{cases}0 & \text { if } p_{j}+\delta<p_{i} \text { or } \beta<p_{i} \\ n_{i}+n_{j} & \text { if } p_{i}<p_{j}-\delta \text { and } p_{i}<\beta-\delta \\ n_{i} & \text { otherwise }\end{cases}
$$

where $i, j \in\{A, B\}$ and $i \neq j$.

\section{Stage 1 (firms' pricing decision)}

In this stage the two firms simultaneously and independently have to set prices while having common knowledge about the market parameters. In the following sections we analyze Stage 1 with respect to different solution concepts. Section 2.1 shows that there is no Bertrand-Nash pricing equilibrium in pure strategies. Sections 2.2, 2.3 and 2.4 report on the mixed strategy equilibrium, the undercut-proof equilibrium and their comparative statics, respectively. 


\subsection{Nonexistence of Bertrand-Nash Equilibrium in Pure Strategies}

In general there exists no equilibrium in pure strategies for the price competition between these two firms because of the presence of a price cycle (see for example Edgeworth (1925) and Maskin and Tirole (1988)). Figure 1 depicts the area of all possible price combinations. A first thing to note is that firms will never set prices below unit costs and not above the consumers' maximum willingness to pay. Setting a price $p_{i}>\beta$ leads to zero profits which will not be the case for some $p_{i}^{\prime} \leq \beta$. Pricing below cost does also result in zero or even negative profits. We can therefore concentrate on the area $\left[c_{A}, \beta\right] \times\left[c_{B}, \beta\right]$.

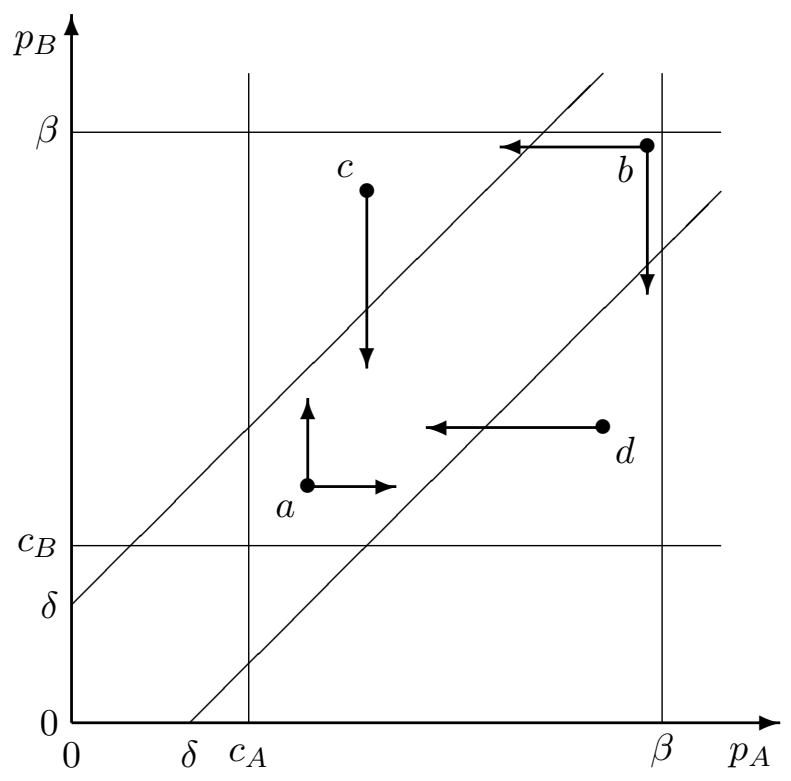

Figure 1: A price cycle a la Edgeworth.

Consider the pair of prices $\left(p_{A}, p_{B}\right)$ indicated by point $a$ in the figure. In this situation, both firms can increase profits by increasing their price (given the price set by the other) as long as the firms stay within the area confined by the restriction $\left|p_{A}-p_{B}\right| \leq \delta$ (the area within the diagonal lines in the figure. Once prices are sufficiently high (indicated by point $b)$, both players have an incentive to undercut the other because the increase in demand outweighs the loss in price. ${ }^{2}$ This brings us to the two triangular areas with points $c$ and $d$. Suppose we are in point $c$. Firm $A$ serves the complete market while firm $B$ suffers from zero demand. Firm $B$ can increase its profit by moving its the price below the diagonal line, thereby gaining $n_{B}$ consumers. A symmetric argument holds for $d$. Clearly, there is no point that is stable against unilateral deviation, and therefore a Bertrand-Nash equilibrium in pure price strategies does not exist.

\footnotetext{
${ }^{2}$ Here we require that the willingness to pay of the consumers is sufficiently high relative to production cost $c_{i}$ and transportation cost $\delta$.
} 


\subsection{Equilibrium in Mixed Strategies}

Although a Bertrand-Nash equilibrium in pure price strategies does not exist, an equilibrium in mixed strategies is known to exist. The model has first been tackled by Shilony (1977). He derived a solution for the case of $n$ firms, $\beta=1$, and $c_{i}=0$ and proved that it is the only symmetric solution. For the "simple" case of two firms the cumulative distribution of prices reduces to

$$
F(p)= \begin{cases}0 & \text { for } 0 \leq p<V-\delta \\ 1-\frac{V}{p+\delta} & \text { for } V-\delta \leq p<\bar{p}-\delta, \\ 1-\frac{V}{\bar{p}} & \text { for } \bar{p}-\delta \leq p<V \\ 2-\frac{V}{p-\delta} & \text { for } V \leq p<\bar{p} \\ 1 & \text { for } \bar{p} \leq p\end{cases}
$$

where $V$ is the value of the game depending on $\delta$

$$
V= \begin{cases}(1+\sqrt{2}) \delta & \text { for } 0 \leq \delta<\frac{1}{2+\sqrt{2}}, \\ \frac{\delta+\sqrt{4 \delta+\delta^{2}}}{2} & \text { for } \frac{1}{2+\sqrt{2}}, \leq \delta<\frac{1}{2}\end{cases}
$$

and $\bar{p}$ is the highest charged price

$$
\bar{p}= \begin{cases}V+\delta & \text { for } 0 \leq \delta<\frac{1}{2+\sqrt{2}} \\ 1 & \text { for } \frac{1}{2+\sqrt{2}}<\delta\end{cases}
$$

For $\delta \geq \frac{1}{2}, F$ degenerates to a pure strategy at $p=1$.

Since we also deal with asymmetric settings and non-zero production costs, we cannot make use of Shilony's results. Therefore we use the software-package Gambit ${ }^{3}$ to calculate the limiting logit equilibria of our setups. Motivated by human subjects' imperfectly optimizing behavior in experiments, McKelvey and Palfrey (1995) proposed the quantal response equilibrium (QRE) in which players choose their strategies stochastically. Actions that induce higher expected payoffs are chosen with higher probabilities. In this way, the QRE specifies the choice probabilities of sub-optimal strategies, or equivalently the likelihood of each possible deviation. In its applications, the noise in players' strategy choices follows a specific distribution, the logit distribution that allows the degree of noisiness to be represented by only one parameter. The resulting QRE is called a logit equilibrium and exists for all parameter values of noise. It generically converges to a unique Nash equilibrium - called the Limiting Logit Equilibrium (LLE) - as the noise approaches zero (see McKelvey and Palfrey (1995)). Structurally the LLE in our setups is comparable to the equilibrium found by Shilony. See Figure 3 for the cumulative distributions of the mixed equilibria of the used parameter settings.

\footnotetext{
${ }^{3}$ http://econweb.tamu.edu/gambit
} 


\subsection{Undercut-Proof Equilibrium}

In order to overcome the problem of nonexistence of a solution in pure price strategies, Morgan and Shy (2000) introduced the undercut-proof equilibrium concept. Although the concept has been introduced more generally, we restrict our digression to the case of two firms because this suffices to demonstrate our concerns. Before we define the undercut-proof equilibrium for the model we have to give a precise definition of undercutting.

Undercutting: A firm is said to undercut the other firm if the firm sets its price low enough to attract the opponent's consumers despite the additional transportation costs the opponent's consumers face. Formally, firm $i$ undercuts firm $j$ if $p_{i}<p_{j}-\delta$.

Undercut-proof equilibrium: In an undercut-proof equilibrium, each firm chooses its price so as to maximize its profit while ensuring that its price is sufficiently low that any rival firm would not undercut. Formally, an undercut-proof equilibrium in our duopoly model is a pair of prices $\left(p_{A}, p_{B}\right)$ satisfying the following conditions for $i, j \in\{A, B\}$ and $i \neq j$ :

(a) For given $p_{j}$ and $q_{j}$, firm $i$ chooses the highest price $p_{i}$ subject to

$$
\pi_{j}=\left(p_{j}-c_{j}\right) q_{j} \geq\left(p_{i}-\delta-c_{j}\right)\left(n_{i}+n_{j}\right)
$$

(the price $p_{i}$ maximizes firm $i$ 's profit, and firm $j$ cannot increase profit by undercutting).

(b) The quantities $q_{j}$ depend on prices $p_{j}$ and $p_{i}$ according to equation (2) at the beginning of the section.

In order to simplify the search for an equilibrium Morgan and Shy (2000) take two further assumptions.

Assumption 1 (participation): All consumers will acquire the product. This assumption is satisfied for a sufficiently high willingness to pay of the consumers. It puts some restrictions on the model's parameters.

Assumption 2 (multi-product solution): Each firm will sell to its own consumer base. This assumption is satisfied when the difference between the prices does not exceed the transportation cost, and again puts some restrictions on the model's parameters.

Owing to the participation assumption, equation (2) simplifies to

$$
q_{i}= \begin{cases}0 & \text { if } p_{i}>p_{j}+\delta, \\ n_{i} & \text { if } p_{j}-\delta \leq p_{i} \leq p_{j}+\delta \\ n_{i}+n_{j} & \text { if } p_{i}<p_{j}-\delta\end{cases}
$$


Owing to the multi-product solution assumption, the quantities in inequalities (6) can be substituted by the consumer bases: $q_{i}=n_{i}$. Moreover, the profit-maximizing prices given the undercutting conditions in inequalities (6) are the prices such that the inequalities bind. Hence, the undercut-proof equilibrium $\left(p_{A}, p_{B}\right)$ satisfies

$$
\left(p_{j}-c_{j}\right) n_{j}=\left(p_{i}-\delta-c_{j}\right)\left(n_{i}+n_{j}\right)
$$

for $i, j \in\{A, B\}$ and $i \neq j$. The system of two linear equations with two unknown variables solves for

$$
p_{i}=c_{j}+\frac{n_{j}^{2}}{n_{i}^{2}+n_{i} n_{j}+n_{j}^{2}}\left(c_{i}-c_{j}\right)+2 \delta+\frac{n_{i}\left(n_{j}-n_{i}\right)}{n_{i}^{2}+n_{i} n_{j}+n_{j}^{2}} \delta .
$$

The prices given by equations (9) behave in some non-intuitive way. In order to illustrate this we will consider three simplified cases.

Case 1 (completely symmetric): We assume that costs as well as the consumer bases are equal, i.e. $c_{A}=c_{B}=c$ and $n_{A}=n_{B}=n$. The resulting UPE prices are

$$
p_{i}=c+2 \delta
$$

Case 2 (asymmetric costs): We assume only consumer bases to be equal, i.e. $n_{A}=n_{B}=$ $n$. The resulting UPE prices are

$$
p_{i}=\frac{1}{3} c_{i}+\frac{2}{3} c_{j}+2 \delta .
$$

It is interesting to see that given equal consumer bases $i$ 's price depends more on her opponent's cost than on her own cost. The intuition is that opponents with higher costs mean a lower threat to be undercut. Hence $i$ can set a rather high price.

Case 3 (asymmetric consumer bases): We assume only costs to be equal, i.e. $c_{A}=$ $c_{B}=c$. The resulting UPE prices are

$$
p_{i}=c+2 \delta+\frac{n_{i}\left(n_{j}-n_{i}\right)}{n_{i}^{2}+n_{i} n_{j}+n_{j}^{2}} \delta .
$$

We see that, given equal costs, the firm with the larger consumer base sets a lower price. The intuition is that a larger consumer base makes it very attractive for the opponent to undercut. To prevent this the firm with the large consumer base has to set a rather low price.

\subsection{Comparative Statics of LLE and UPE}

Both solution concepts described in Sections 2.2 and 2.3 do follow their particular rationale. In the LLE firms focus on the maximization of the own payoff given the opponents' play. This can be considered as first order consideration. Players in the UPE look one step further 
because they take a potential reaction of the opponent into account. Moreover their paradigm is in a way defensive because maximization only takes place as long as the opponent does not have an incentive to move to an undercutting strategy. We see this as second order consideration.

The different paradigms lead to opposite comparative statics results in the asymmetric settings. The LLE predicts that the firm with the lower cost and the firm with the smaller consumer base set lower prices (see Figure 3). The intuition behind that is that for both respective types of firms it is very attractive to undercut the opponent. In the asymmetric cost case the low cost firm will not suffer too much from the low price because its marginal win is still substantial. In the asymmetric consumer base case the firm with the small consumer base can gain a lot by undercutting. Analogous considerations lead to the LLE prediction that the firm with the high cost and with the large consumer base, respectively, set high prices.

This qualitative prediction of the LLE is in contrast to UPE. There because of the second order considerations the firm with the lower cost and the firm with the smaller consumer base will set the higher price. In the asymmetric cost case this behavior is motivated by the opponent's limited possibility to undercut. In the asymmetric consumer base case the opponent finds it not attractive to increase its consumer base only marginally by undercutting while losing quite something due to the low price.

It would be exaggerated to expect that behavior of human subjects in an experiment would exactly match any theory with a point prediction because there are too many unmeasured influences. It can be expected however, that if behavior follows a certain theory then the comparative statics of this behavior should be consistent with the comparative statics of the theory. This is, what the following experiment was set out for.

\section{The Experiment}

\subsection{Experimental Design}

The experiment was set up following the model described in Section 2. Two duopolists had to set prices simultaneously. Consumers were simulated by the computer, that means that they maximized their utility. Depending on the prices, their transportation costs and their willingness to pay they either bought from firm $A$, firm $B$, or did not buy at all.

For every session 14 subjects were invited to the laboratory. Half of them were randomly assigned to be firm $A$. The other half were assigned to be firm $B$. All market parameters were common knowledge (the size of consumer bases $n_{A}, n_{B}$, the individual production costs $c_{A}, c_{B}$, the maximum willingness to pay $\beta$, and the transportation cost $\left.\delta\right) .{ }^{4}$

\footnotetext{
${ }^{4}$ In order to avoid confusion among the subjects and to put them into the same setting, the instructions and the computer screens did not talk about firm $A$ 's and $B$ 's parameters but only about the "own" parameters and the "other" firm's parameters.
} 
The model resembles a one-shot game. However, we also wanted to investigate mature behavior and thus conducted 20 rounds. This was common knowledge. For each round firms $A$ were randomly matched to firms $B$. They did not learn whom they interacted with and whom they were going to interact with. The individual parameters and the market parameters remained stable throughout this 20 rounds. The feedback which was given to the firms comprised their price, the other's price, the resulting individual consumer demands and the individual profits. Additionally we provided each subject with his (and only his) accumulated profit.

In order to test the comparative statics of both, the UPE as well as the LLE, we conducted three different treatments, one complete symmetric, one with symmetric consumer bases but asymmetric costs and one with symmetric costs but asymmetric consumer bases. Table 1 shows the particular parameter settings as well as the corresponding UPE prices and the expected LLE prices.

\begin{tabular}{lcccc}
\hline & & $\begin{array}{c}\text { Treatment 1 } \\
\text { completely } \\
\text { symmetric }\end{array}$ & $\begin{array}{c}\text { Treatment 2 } \\
\text { asymmetric } \\
\text { cost }\end{array}$ & $\begin{array}{c}\text { Treatment 3 } \\
\text { asymmetric } \\
\text { consumer base }\end{array}$ \\
\hline basic utility & $\beta$ & 100 & 100 & 100 \\
transportation cost & $\delta$ & 20 & 20 & 20 \\
consumer base & $n_{A}$ & 60 & 60 & 80 \\
production cost & $n_{B}$ & 60 & 60 & 40 \\
& $c_{A}$ & 30 & 15 & 30 \\
\hline UPE predictions & $c_{B}$ & 30 & 45 & 30 \\
\multirow{4}{*}{ LLE predictions } & $p_{A}$ & 70 & 75 & 65 \\
& $p_{B}$ & 70 & 65 & 74 \\
\hline conducted sessions & $p_{A}$ & 81.86 & 74.62 & 77.96 \\
total number of subjects & 81.86 & 82.80 & 74.32 \\
\hline
\end{tabular}

Table 1: Conducted treatments with the predictions of the undercut-proof equilibrium (UPE) and the Nash equilibrium in mixed strategies (LLE). Note: The exact values for the UPE prediction using continuous prices are $p_{A}=64.29$ and $p_{B}=72.86$. Through the discretization, however, equilibrium prices shift slightly upwards. LLE predictions are expected prices.

To assist them in making their decisions, subjects could use a profit calculator which was built into the experimental software. Subjects could enter hypothetical prices for their own and the other firm and received the resulting potential profits of both firms as information.

\subsection{Experimental Procedure}

The experiment was computerized and conducted in the experimental computer laboratory at the University of Maastricht (Faculty of Economics and Business Administration). The 
software was programmed within the z-Tree toolbox (Fischbacher 1999). Subjects were invited via email to register for a "market experiment" on a website. In total we conducted 15 sessions with 14 subjects each (208 subjects in total). ${ }^{5}$ In each session subjects received written instructions (see the appendix for the instructions of the symmetric treatment). They could study the instructions at their own pace and ask clarifying questions privately. Before the experiment started every subject had to answer some control questions correctly (see appendix). After the experiment subjects received a short questionnaire with demographic questions and eventually they were paid off in cash. For the conversion of ECU (Experimental Currency Units) to Euro we used different exchange rates for different firm types and treatments. We did this because we wanted to eliminate fairness concerns as much as possible. Getting the long or the short end in the quite asymmetric treatments might lead people to feel sorry or envious with the other type of firms. To avoid this problems we had to keep subjects uncertain about the amount of real money others get. Since subjects could infer the profits from prices and demands, the only way is to conceal the exchange rate. Each subject knew only his or her own personal exchange rate. Additionally, everyone received the explicit information that the exchange rate of others might differ from their own, but none was informed about the actual exchange rate of others. Doing so means that we give both equilibrium concepts a good shot. The exchange rates were calibrated by the UPE prediction (i.e. if all subjects had played the UPE strategy everybody would have received the same amount of money. The average payoff of a subjects was $€ 15$.- with a session lasting for about 90 minutes.

\section{Results}

In order to give the reader a general intuition about the data we present some aggregated results first. Figure 2 shows the development of the average prices over time. Average prices start quite closely together within the interval $[61,67]^{6}$ and rise during rounds while also getting more dispersed across types.

From this first overview it becomes already clear that the data is more consistent with the LLE prediction rather than with the UPE prediction. For Treatment 2 with asymmetric production costs the firm with higher production cost is also setting a higher price. For Treatment 3 with asymmetric consumer bases the firm with a higher consumer base is also charging a higher price. Furthermore, average prices do increase during rounds and arguably come close to the respective average LLE prices. How well the LLE prediction is doing in explaining the results is demonstrated by Figure 3. It shows that the cumulative distributions of the prices in the last five rounds per treatment and firm type matches the LLE prediction

\footnotetext{
${ }^{5}$ For one session in the symmetric treatment only 12 subjects showed up.

${ }^{6}$ Initial average behavior seems to be close to 65 which is the average price if everyone played exactly the middle of one's strategy set.
} 

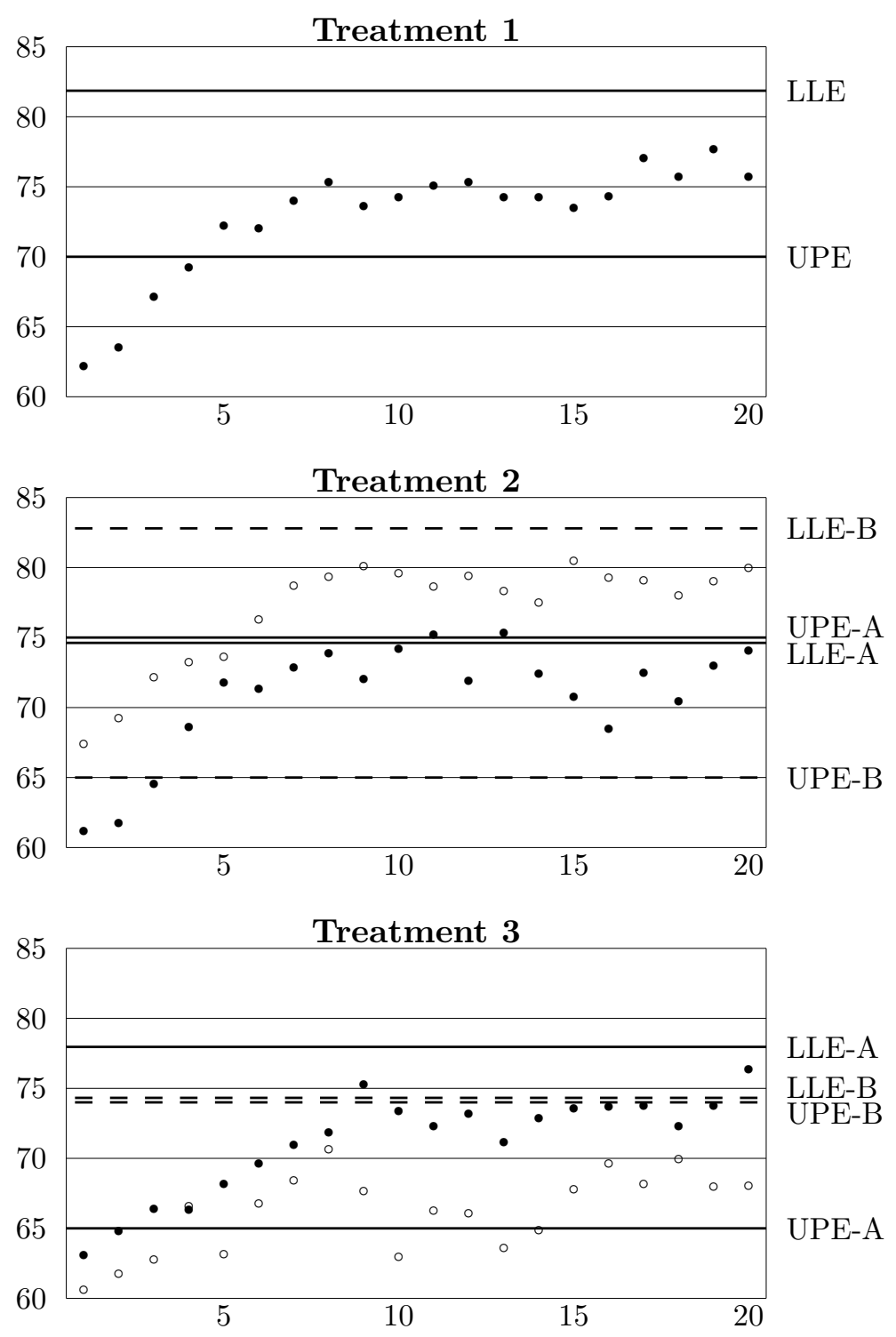

Figure 2: Average prices per round (for treatments 2 and 3 the solid dots correspond to firm $A$ and the circles to firm $B$ ).

quite closely and much better than the UPE prediction. Although prices are slightly lower than the LLE prediction, the structure of the cumulative distributions look very similar. ${ }^{7}$

In the following subsections we will analyze the data in more detail and provide statistical tests for our results.

\footnotetext{
${ }^{7}$ The logit equilibrium with infinite noise will lead to a uniform distribution over prices. As the data is in between the two extreme logit equilibria (with infinite and zero noise, respectively), there exist parameters of noise that lead to an even better fit. This indicates that the shifts towards lower prices can be explained by the presence of bounded rationality.
} 

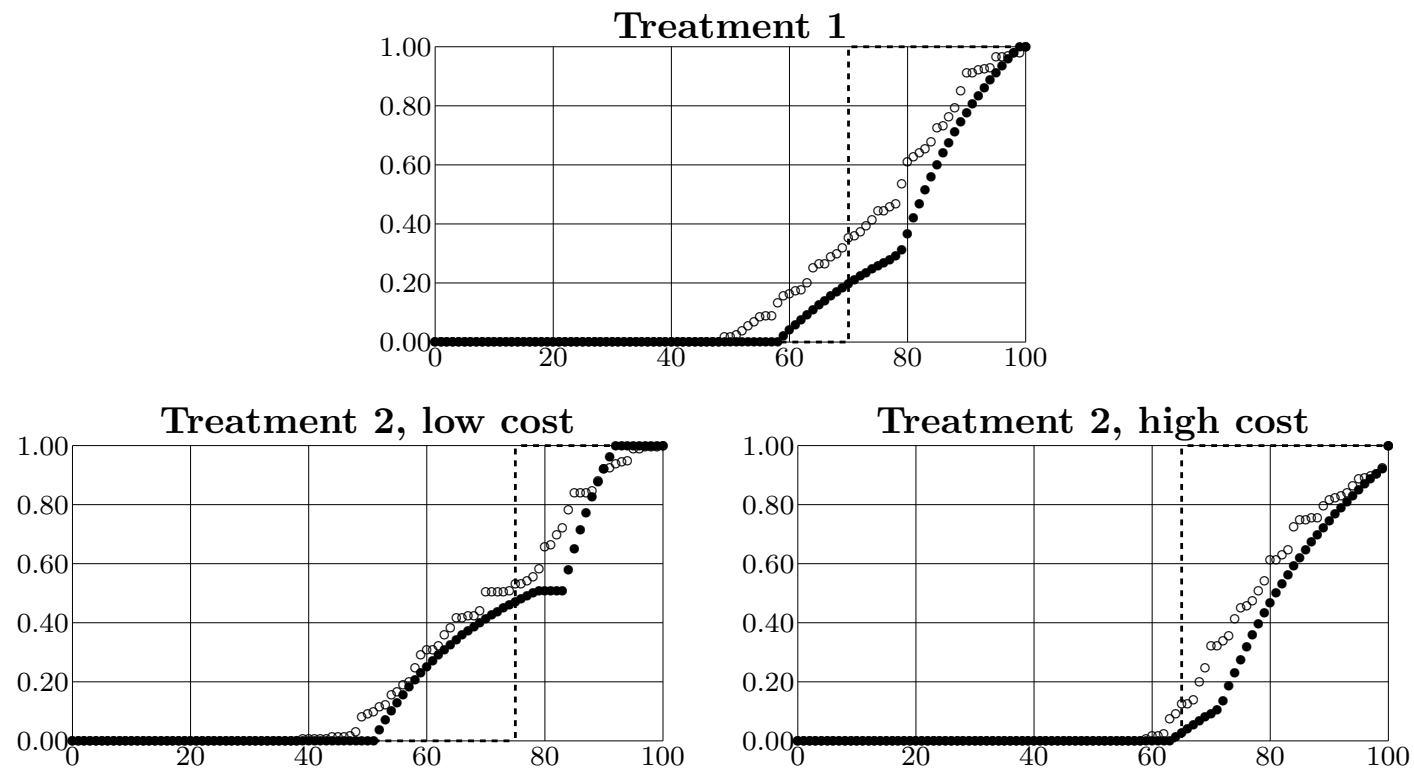

Treatment 3, large consumer base
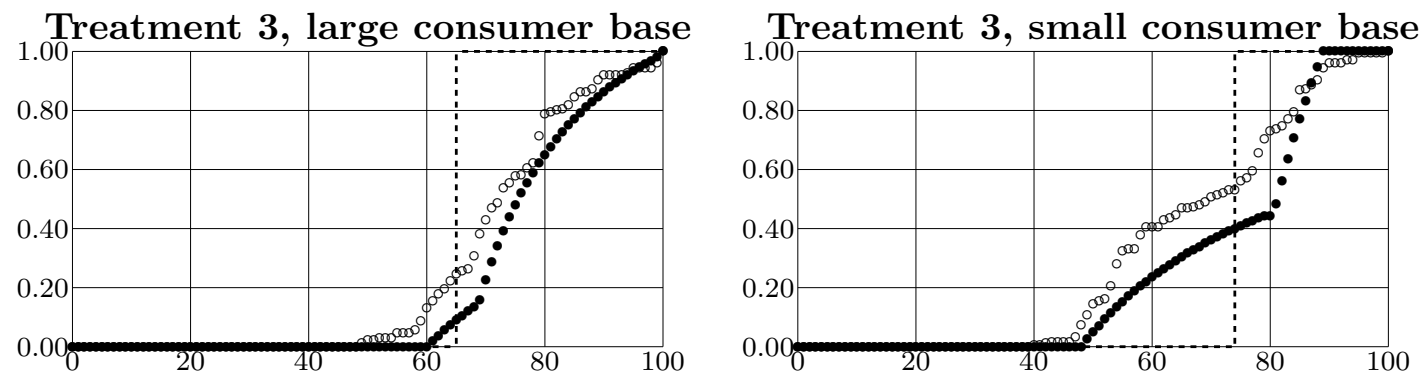

Figure 3: Cumulative distribution of prices in the last five rounds (circles) versus LLE prediction (solid dots) and UPE prediction (dashed line).

\subsection{Prices}

In order to test the result that prices on average are consistent with the comparative statics of the LLE rather than the one of UPE we calculate the average price per subject. Using a Mann-Whitney $U$ test we do not find a significant difference between average prices of firms $A$ and $B$ in Treatment 1 . For Treatments 2 and 3 we find that firms with higher costs and firms with higher consumer base do set significantly higher prices (see Table 2).

Strictly speaking the average prices are not independent across subjects, since subjects interacted for 20 rounds and no perfect stranger matching could be conducted. ${ }^{8}$ In order to be on the safe side we also calculated the average prices per session and firm type and conducted Wilcoxon signed-rank tests on the session level (see Table 2). The results of the previous tests were confirmed although at lower significance levels.

Eventually we repeated the tests with only taking into account the last five rounds in order to investigate the more mature behavior. The results become a bit weaker (see Table

\footnotetext{
${ }^{8}$ However, each subject did not know whom he/she was matched to, neither ex-ante nor ex-post.
} 


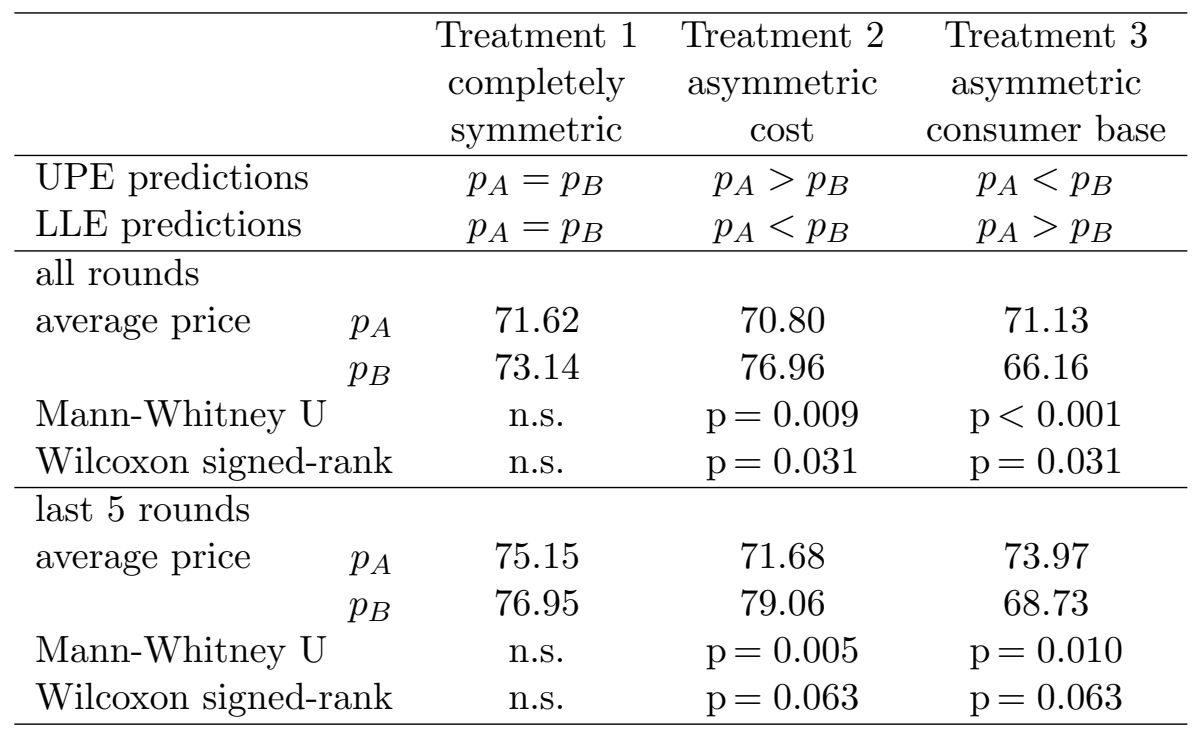

Table 2: Average prices per treatment and player's type. Mann-Whitney U tests are based on the average prices of subjects as independent observation. Wilcoxon signed-rank tests are based on sessions as independent observations. Tests are two-sided for Treatment 1 and one-sided for Treatments 2 and 3.

2 , bottom part). Nevertheless we may summarize the findings in the observation that prices oppose the comparative statics prediction of the UPE and are in line with the comparative statics prediction of the LLE.

\subsection{Undercutting Behavior}

While undercutting does per definition not occur in the UPE it might happen in the LLE. It is therefore interesting to look at the undercutting behavior in particular for the asymmetric treatments and to compare it with the actual behavior. Table 3 shows the relative frequencies of cases where undercutting took place.

Following the LLE prediction, in the asymmetric treatments undercutting should be more frequent with low-cost firms and with the high consumer base firms, respectively. Table 3 shows that this is indeed the case. Applying a Wilcoxon signed-rank test on the basis of sessions as independent observations the results are found to be significant in Treatments 2 and 3 .

\subsection{Use of Profit Calculator}

As mentioned in Section 3.1 subjects had the possibility to calculate their own and their opponent's profit by submitting hypothetical prices to a profit calculator. This data was recorded. Though there was no other incentive to use it than the value of the information subjects got from it, the data provides some insight into the reasoning process. The aggregate 


\begin{tabular}{lccc}
\hline & $\begin{array}{c}\text { Treatment 1 } \\
\text { completely } \\
\text { symmetric }\end{array}$ & $\begin{array}{c}\text { Treatment 2 } \\
\text { asymmetric } \\
\text { cost }\end{array}$ & $\begin{array}{c}\text { Treatment 3 } \\
\text { asymmetric } \\
\text { consumer base }\end{array}$ \\
\hline UPE prediction & $0 \%$ & $0 \%$ & $0 \%$ \\
$\operatorname{Pr}\left(p_{A} \ll p_{B}\right)$ & $0 \%$ & $0 \%$ & $0 \%$ \\
$\operatorname{Pr}\left(p_{B} \ll p_{A}\right)$ & & & \\
LLE prediction & $9.9 \%$ & $25.4 \%$ & $3.8 \%$ \\
$\operatorname{Pr}\left(p_{A} \ll p_{B}\right)$ & $9.9 \%$ & $2.3 \%$ & $17.4 \%$ \\
$\operatorname{Pr}\left(p_{B} \ll p_{A}\right)$ & & & \\
data all rounds & $14.1 \%$ & $21.4 \%$ & $5.7 \%$ \\
$\operatorname{Pr}\left(p_{A} \ll p_{B}\right)$ & $10.1 \%$ & $6.1 \%$ & $20.7 \%$ \\
$\operatorname{Pr}\left(p_{B} \ll p_{A}\right)$ & $\mathrm{n} . \mathrm{s}$. & $\mathrm{p}=0.031$ & $\mathrm{p}=0.031$ \\
Wilcoxon signed-rank & & & \\
\hline data last 5 rounds & $16.5 \%$ & $24.6 \%$ & $7.4 \%$ \\
$\operatorname{Pr}\left(p_{A} \ll p_{B}\right)$ & $9.4 \%$ & $5.1 \%$ & $23.4 \%$ \\
$\operatorname{Pr}\left(p_{B} \ll p_{A}\right)$ & $\mathrm{n} . \mathrm{s}$. & $\mathrm{p}=0.031$ & $\mathrm{p}=0.031$ \\
Wilcoxon signed-rank & & & \\
& & & \\
\hline
\end{tabular}

Table 3: Undercutting behavior across treatments. $\operatorname{Pr}\left(p_{A} \ll p_{B}\right)$ and $\operatorname{Pr}\left(p_{B} \ll p_{A}\right)$ denote the probabilities of $A$ undercutting $B$ and vice versa. Note: Tests are two -sided for Treatment 1 and one-sided for the Treatments 2 and 3. They are based on sessions as independent observations. The null-hypotheses are that the frequencies are equal for Treatment 1 and that their relationship is opposite to the LLE prediction in Treatments 2 and 3.

pattern of usage is as one typically expects from such a tool. We can see a drop in usage during rounds (from an average of about 5 times in round 1 to roughly 3 times in rounds 8 to 10 and eventually to about 2 times in rounds 16 to 20 ). $51.4 \%$ of the subjects used the profit calculator only 0 to 50 times in total, 34.3\% used it between 51 and 100 times, $8.6 \%$ between 101 and 150 times, 3.6\% between 151 and 200 times and $2.1 \%$ used it more than 200 times. We classify the usage of the profit calculator into two different behaviors, UPE behavior and Nash behavior. ${ }^{9}$

UPE behavior: The typical process to find a UPE strategy (without using sophisticated analysis) is to assume a price for oneself, and then check whether the opponent has an incentive to undercut. Depending on that the assumed price can be increased or decreased and undercutting incentives of the opponent could be checked anew. This process should therefore result in more frequent changes of the others price than in the own price.

Nash behavior: The typical (non-sophisticated) process underlying Nash is characterized by the idea of finding a best response. Given an expectation of the opponent's price

\footnotetext{
${ }^{9}$ We call it Nash behavior, because it is not only characteristic for LLE but for any sort of Nash equilibrium.
} 
one tries to find the best response to it. Nash behavior should therefore result in more frequent changes of the own price than of the other's price.

Two consecutive requests to the profit calculator could either differ by a change in the own hypothetical price, in the other hypothetical price, or in both. ${ }^{10}$ In order to categorize subjects into UPE and Nash types we count and compare the frequencies of the corresponding price changes. A higher number of changes in the own hypothetical price correspond to a Nash type. A higher number of changes in the others hypothetical price corresponds to an UPE type.

Figure 4 shows a scatter plot where each subject is characterized by the changes. Points below the diagonal represent Nash types because they change their own price more often. Correspondingly, points above the diagonal represent UPE types. The analysis resulted in 122 Nash types, 68 UPE types and 15 neither Nash nor UPE. ${ }^{11}$

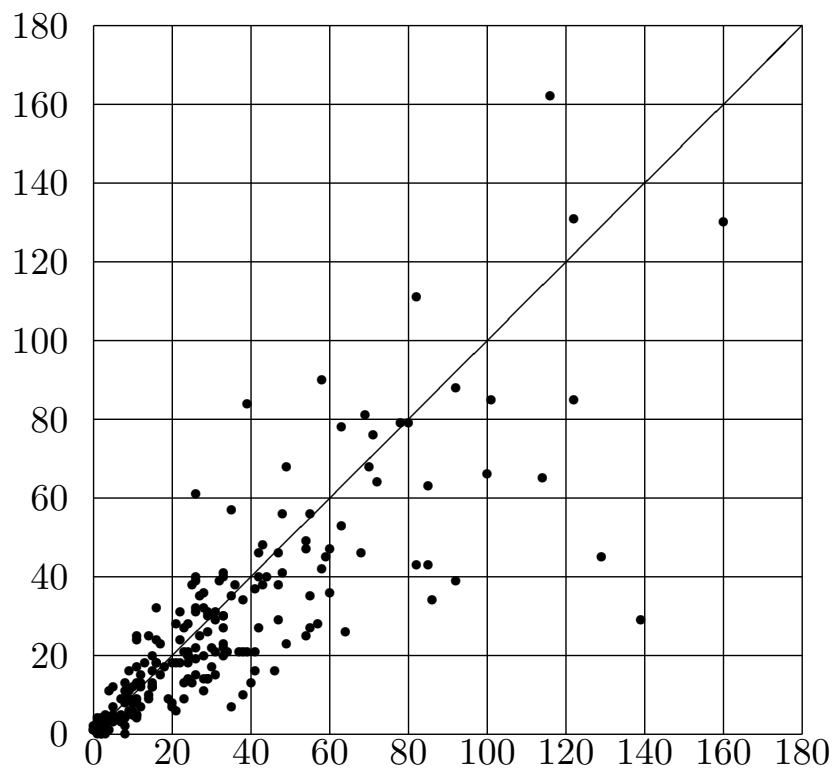

Figure 4: Classification into Nash types and UPE types ( $x$-axis: changes in own price; $y$-axis: changes in other price).

\subsection{Adaptation Behavior}

Nash behavior is based on the idea of finding a best response to the other players' behavior. To do so, a player has to make up beliefs about others' actions. For the following analysis we start out from the simple assumption that players $i$ believe their opponents to play the

\footnotetext{
${ }^{10} \mathrm{~A}$ change was recorded as soon as the subject pressed the "CALCULATE" button of the software anew.

${ }^{11} 3$ subjects were not classifiable since their use of the profit calculator was not sufficiently frequent to have at least one change.
} 
same strategy as in the round before $\left(p_{j}^{t}=p_{j}^{t-1}, i \neq j\right) .{ }^{12}$ The best response to this belief is either to maximize the price while keeping the own consumer base or to maximize demand by undercutting. The first strategy requires one to set the current price $p_{i}^{t}=p_{j}^{t-1}+\delta=p_{j}^{t-1}+20$. The second strategy requires one to set $p_{i}^{t}=p_{j}^{t-1}-\delta-\varepsilon=p_{j}^{t-1}-21$.

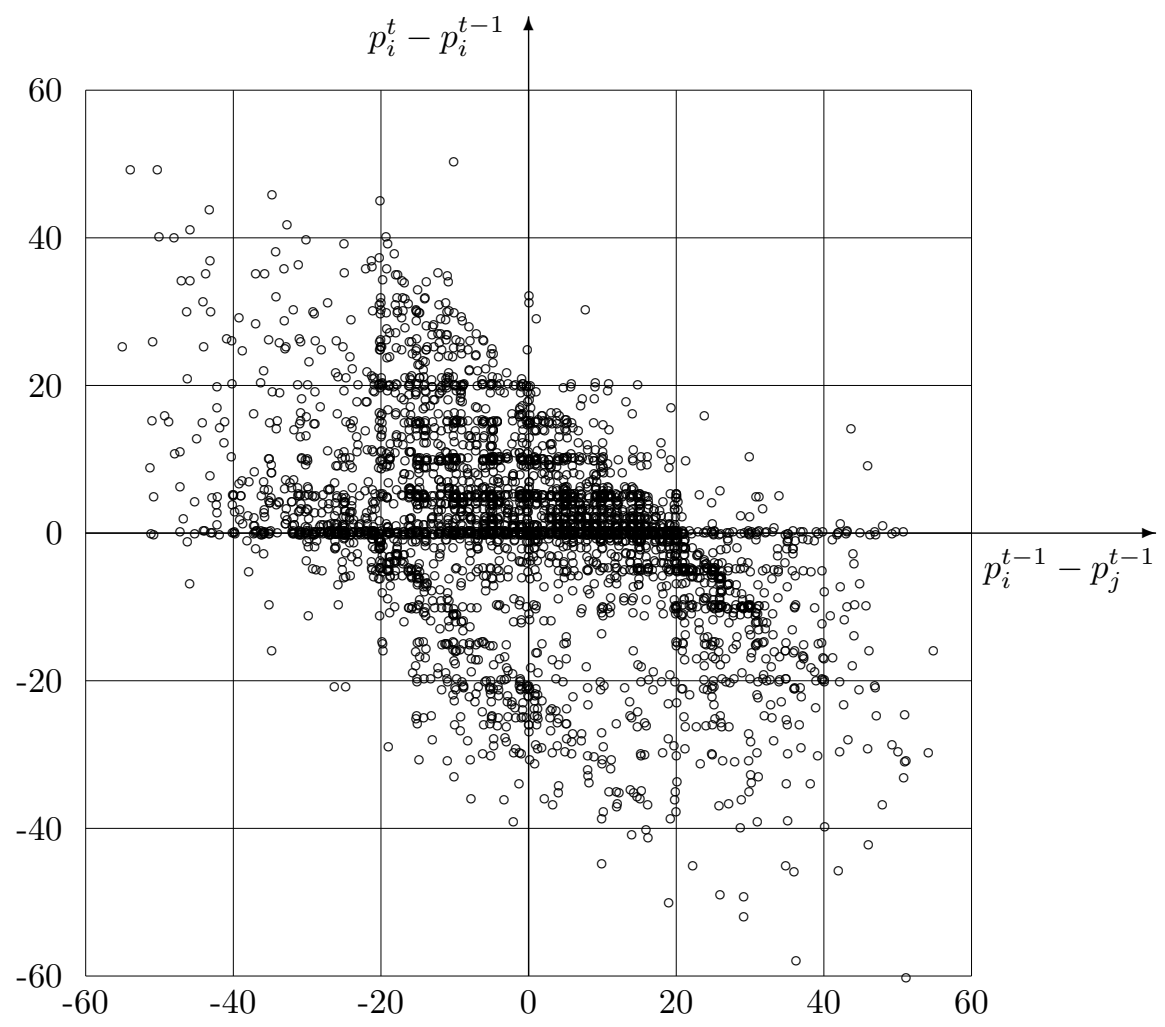

Figure 5: Changes in prices from round $t-1$ to $t$ dependent on the difference between firms prices in round $t-1$.

Figure 5 shows how players changed their price $\left(p_{i}^{t}-p_{i}^{t-1}\right)$ dependent on the difference between their and their opponents' price $\left(p_{i}^{t-1}-p_{j}^{t-1}\right)$. Although the data looks quite dispersed there is some structure to be recognized. First, there exists quite a number of cases in which players did not change their price (cases located on the x-axis). Second, one can recognize two imaginary downwards sloping lines, the first from coordinates $(-20,40)$ to $(40,-20)$ and the second from $(-20,0)$ to $(0,-20)$. The first line represents the price maximizing strategy. Subjects do raise their prices but only as much as to prevent being undercut. The second line represents demand maximizing, i.e. undercutting. Subjects change their prices in order to get $\delta+1$ below the opponent.

\footnotetext{
${ }^{12}$ Although subjects were informed that their opponent will be randomly determined from round to round the results will show that this assumption is plausible.
} 


\subsection{Individual Behavior}

A mixed strategy equilibrium in games with random matching may be interpreted in two different ways. One possibility is that subjects do indeed mix their strategy and play different actions across rounds. On the other hand there is no need of doing so. Given that subjects are randomly matched with others they might also play consistently one particular action. This "mass-action" interpretation of the mixed strategy equilibrium as a steady state in a large population has already been mentioned in the dissertation of Nash (1950). Our data allows us to shed some light on this question. Each subject played 20 rounds and thus gives us a distribution of 20 actions which can be tested against the theoretical distribution of the LLE predictions. Table 4 shows that we can reject the hypothesis that subjects mix individually according to the LLE for 145 out of 208 subjects at conventional significance levels $(\mathrm{p}<5 \%)$. For 47 we cannot reject this hypothesis and 16 cases are borderline cases $(5 \% \leq \mathrm{p}<10 \%)$. The data strongly supports a population interpretation of the mixed strategy equilibrium.

\begin{tabular}{cc}
\hline $\begin{array}{c}\text { Level of } \\
\text { significance }\end{array}$ & $\begin{array}{c}\text { Number of } \\
\text { subjects }\end{array}$ \\
\hline $\mathrm{p}<0.001$ & 89 \\
$0.001 \leq \mathrm{p}<0.005$ & 23 \\
$0.005 \leq \mathrm{p}<0.01$ & 9 \\
$0.01 \leq \mathrm{p}<0.05$ & 24 \\
$0.05 \leq \mathrm{p}<0.1$ & 16 \\
not significant & 47 \\
\hline
\end{tabular}

Table 4: Mixing on an individual level or on a population level. Note: Significance levels are based on Kolmogorov-Smirnov tests for which we compared the distribution of 20 round prices of each particular subject to the theoretical distribution of the corresponding LLE prediction.

\section{$5 \quad$ Summary and Conclusions}

The experiment provided a test of two different behavioral paradigms for markets with differentiated products. In particular we investigated the performance of the Limiting Logit Equilibrium (LLE) and the Undercut-Proof Equilibrium.

The overall evidence of our data speaks clearly in favor of Nash behavior and against UPE. The mature behavior (prices of the last five rounds) matches the theoretical prediction of the LLE quite closely. In asymmetric settings, firms with higher cost as well as firms with larger consumer bases set significantly higher prices. This result renders the UPE very questionable. Furthermore, while the UPE does avoid undercutting behavior by definition, undercutting takes place and is quite similar to the predicted figures by LLE.

Further evidence against the UPE is provided by Orzen and Sefton (2004) who also investigated differentiated product markets. In their setup, subjects had to set a price repeatedly 
for 50 rounds with fixed matching. Their treatment varied in the number of players in the market ( 2 players versus 4 players). The UPE predicts the same prices in both treatments while the mixed strategy equilibrium found by Shilony (1977) predicts a lower price with 4 players. The aggregated data matches the mixed strategy equilibrium much better than UPE. Moreover the equality of average prices in duopolies and quadrupolies can be rejected in favor of the mixed strategy equilibrium (Mann-Whitney $\mathrm{U}, \mathrm{p}<0.001$ ).

The analysis of the profit calculator data provides us with some although limited insights to the way subjects thought when making up their decisions. The majority changes its own price more frequently than the price of its opponent and this behavior was more pronounced than for the opposite cases.

The interpretation of the results should not be mistakenly lead to the assumption that individual subjects are able to find the appropriate strategy mixture in differentiated product markets. It is rather on the population level where the mixed strategy equilibrium gains explanatory power.

One of the reasons for getting the clear support for the Nash equilibrium might also be the way subjects were paid off and the matching scheme. Since subjects only knew their own exchange rate and not the one of others, any kind of social comparison was eliminated. Moreover, the probability of being matched to the same person again in the following round was rather low. Thus social preferences and reciprocity can hardly trigger the price setting behavior.

Given the data, there is no evidence to support the idea of the UPE in our experimental setting. However, we investigated this question only in a static setting. Our experiment resembled a one-shot situation as much as this was possible. It is not clear, however, how subjects would behave in a dynamical setting. The nature of the UPE makes it probably more suitable for settings where the opponent can react on one's price. As mentioned in the introduction the UPE faces quite some similarity with the situation of a Stackelberg-leader in a sequential game. In this case, however, the comparative statics do coincide and it is questionable whether the UPE does better. Another dynamic setting could be the repeated game with short run price commitments as for instance an alternating move game. Such a case remains to be investigated.

\section{References}

1. Bester, H. (1992), "Bertrand Equilibrium in a Differentiated Duopoly," International Economic Review, 33, 433-448.

2. Edgeworth, F.Y. (1925), "The Pure Theory of Monopoly," In: Edgeworth, F.Y. (Ed.), Paper Relating to Political Economy, vol.1, Burt Franklin, New York, 111-142. 
3. Fischbacher, U. (1999), "z-Tree. Toolbox for Readymade Economic Experiments," IEW Working paper 21, University of Zurich.

4. Hotelling, H. (1929), "Stability in Competition," Economic Journal, 39, 41-57.

5. Huck, S., H.-T. Normann, and J. Oechssler (2000), "Does Information about Competitors' Actions Increase or Decrease Competition in Experimental Oligopoly Markets," International Journal of Industrial Organization, 18, 39-57.

6. KüBler, D. AND W. Müller (2002), "Simultaneous and Sequential Price Competition on Heterogeneous Duopoly Markets: Experimental Evidence," International Journal of Industrial Organization, 20, 1437-1460.

7. Maskin, E. And J. Tirole (1988), "A Theory of Dynamic Oligopoly, II: Price Competition, Kinked Demand Curves, and Edgeworth Cycles," Econometrica, 56, 571-599.

8. McKelvey, R.D. and T.R. Palfrey (1995), "Quantal Response Equilibria for Normal Form Games," Games and Economic Behavior, 10, 6-38.

9. Morgan, P.B. And O. Shy (2000), "Undercut-Proof Equilibria," mimeo.

10. Nash, J.F. (1950), Non-cooperative Games, PhD dissertation, Princeton University, published in H.W. Kuhn and S. Nasar (2002), The Essential John Nash, Princeton University Press, Princeton, New Jersey.

11. Orzen, H. And M. Sefton (2004), "Mixed Pricing in Oligopoly: An Experiment," CeDEx Working Paper No. 2004-18.

12. Shilony, Y. (1977), "Mixed Pricing in Oligopoly," Journal of Economic Theory, 14, 373-388.

13. Shy, O. (2001), The Economics of Network Industries, Cambridge University Press, Cambridge, Mass.

\section{Appendix}

\section{A Instructions for Market Experiment}

Dear participant, thank you for taking part in this experiment! It will last about $11 / 2$ hours. You will be compensated according to your performance during the experiment. In order to ensure that the experiment takes place in an optimal setting, we would like to ask you to follow the general rules during the whole experiment:

- please do not communicate with your fellow students! 
- please do not forget to switch off your mobile phone!

- read the instructions carefully. If something is not well explained or any question turns up now or at any time later in the experiment, then ask one of the experimenters. Do, however, not ask loud, but raise your hand! We will clarify questions privately.

- you may take notes on this instruction sheet if you wish.

- after the experiment, please remain seated till we paid you off.

- if you do not obey the rules, the data becomes useless for us. Therefore we will have to exclude you from this experiment and you will not receive any compensation.

Your decisions are anonymous. Neither of your fellow students nor anybody else will ever learn them from us.

\section{The situation:}

Suppose there are two cities each containing one producer. Both producers produce the same product. Each city contains consumers who value the product at $100 \mathrm{ECU}$ and will not spend more than this value to acquire the product. Each consumer has two possibilities to buy. Either he buys from the local producer in his own city or he buys from the producer in the other city. If a consumer buys the product from the local producer, he simply pays the product price of the local producer. If a consumer decides to buy the product from the producer in the other city, he pays this producer's price and additionally incurs a transportation cost of 20 ECU to bring the product from the other to his own city. Consumers will take the cheapest possibility. If both possibilities are equally cheap then they buy from their local producer. Each consumer will buy only one unit of the product (given that it costs him not more than 100 ECU in total).

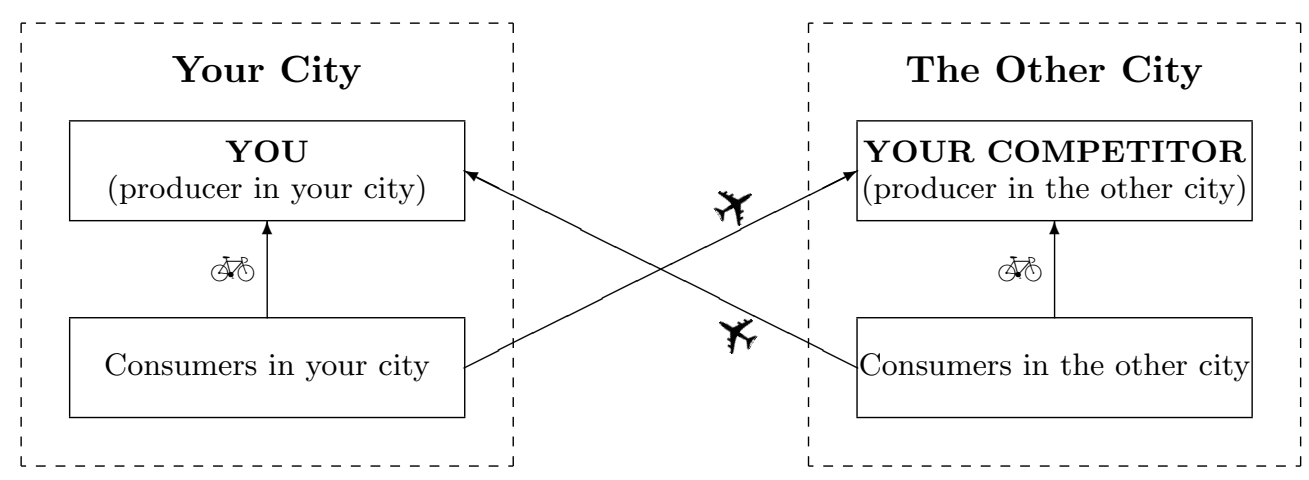

You are the producer in one of the cities. Your city contains 60 consumers and the other city contains 60 consumers. You face a production cost of 30 ECU per unit and the other producer (represented by another participant in the lab) faces a production cost of $30 \mathrm{ECU}$ 
per unit. Production costs are only incurred for the units actually sold. Your task is to set a price for your product knowing that the other producer simultaneously sets a price for his product. After prices have been set, the computer will calculate the number of consumers. Consumers in both cities will choose their cheaper alternative and thereby take into account the transportation cost if they buy from the producer in the other city (as described in the rules above). From these numbers your profit can be calculated. The profit is equal to total revenue (price times quantity sold) minus total cost (cost times quantity sold).

The relevant numbers above are summarized in the following table:

Consumers valuation:

Transportation cost:

Number of consumers in your own city: $\quad 60$

Number of consumers in the other city: 60

Your unit cost:

Unit cost of producer in the other city: 30

\section{The procedure:}

In total, there are 20 rounds in this experimental session. In each round you face the same situation. In every round you are randomly matched to another participant who acts in the role of the other producer (he also has full information on consumer numbers and production costs).

You go through the following steps:

- look at the previous rounds' prices set by you and by those you were matched to (in all rounds except the first).

- a profit calculator is given which allows you to compute your profit in different scenarios. By typing in fictitious prices from you and the other producer you can simply try out different possibilities and their consequences without commitment to a certain price.

- now you set the price of your product.

- look at the result and your obtained profit.

- a new round starts. You will be randomly matched to another participant.

Please, make your decisions carefully - your reward will depend on your performance during the experiment. ECUs are transformed into Euros according to the following conversion rate:

$$
1000 \mathrm{ECU}=0.3125 \text { Euros }
$$


Other participants may have different conversion rates. At the end of the experiment, we would like to ask you to complete a short on-screen questionnaire.

Thank you again and good luck with the experiment!

\section{Questionnaire}

Please, answer the following questions! One of the experimenters will go round, check the answers and discuss any problems.

Please fill in your subject id:

\begin{tabular}{|l|l|l|}
\hline Question & YES & NO \\
\hline Do consumers buy your product when you set a price higher than 100 ECU? & & \\
\hline When you set your price below your costs, do you make a profit? & & \\
\hline $\begin{array}{l}\text { When your price is more than 20 ECU less than the other producer's price, } \\
\text { do the consumers in the other city buy the other producer's product? }\end{array}$ & & \\
\hline Other participants may have another conversion rate from ECU into Euro. & & \\
\hline
\end{tabular}

